\title{
O RÁDIO LOCAL E O COMPORTAMENTO DA INFORMAÇÃO NA NOVA ORDEM GLOBAL
}

\author{
The local radio and the information behavior in \\ the new global order
}

Leandro Ramires Comassetto ${ }^{1}$

\section{Resumo}

Este trabalho é uma síntese da tese "A voz da aldeia: o rádio local e o comportamento da informação na nova ordem global". Trata-se de um estudo de caso do rádio no Oeste de Santa Catarina (Brasil), região que mantém uma relação histórica com esse meio de comunicação. A investigação, centrada no trabalho jornalístico e na análise do conteúdo veiculado pelas emissoras, procurou perceber até que ponto o rádio é um veículo verdadeiramente local, voltado às necessidades de sua audiência, e que cumpre função relevante nas comunidades em que está inserido. A pertinência do estudo evidencia-se numa época em que a comunicação assume caráter cada vez mais globalizado, dominada por grandes corporações de mídia, que absorvem e influenciam os veículos menores.

Palavras-chave: Rádio local; Oeste de Santa Catarina; Informação; Regionalização; Globalização.

\section{Abstract}

The present text is a synthesis of the thesis "The village voice: local radio and information behavior in the new global order". It is a study of case on radio stations in the west of the state of Santa Catarina (Brazil), a region that maintains a historical relation with this medium. The investigation, focused on journalism and in the analysis of the information broadcasted by the stations, has aimed at knowing if the radio is actually a local medium, targeting its audience needs, and if it plays an important role for the communities that it reaches. The present study comes as a result of the concern about the time in which communication becomes more and more global, controlled by huge media corporations, that absorb and influence smaller stations. Keywords: Local radio; Santa Catarina west region; Information; Regionalism; Globalization.

Leandro Ramires Comassetto é Doutor em Comunicação Social pela PUCRS (Brasil) e professor da UnC - Universidade do Contestado (Concórdia - SC). Endereço: Rua Victor Sopelsa, 3000 - 89700-000 Concórdia - SC. Fone: (49) 442-3179. E-mail: ramires@uncnet.br. Homepage: www.uncnet.br. 


\section{0 rádio na era da globalização}

A transformação operada nas comunicações, sobretudo a partir das duas últimas décadas, chama à reflexão sobre o futuro do rádio local. A pergunta que vem à tona é até quando os meios que atuam em âmbito local, voltados à discussão das problemáticas do entorno mais imediato, resistirão ao processo de concentração fomentado pela onda de fusões e convergências, que favorece os maiores grupos de mídia, potencializando suas ações tanto em termos de abrangência quanto de exploração de novos negócios.

A comunicação, na atualidade, é um negócio que transcende os veículos tradicionais. Conjuga ferramentas informáticas e telecomunicacionais e transita da informação ao entretenimento. Está dominada por conglomerados que atuam em redes ou cadeias, seja em nível nacional ou internacional, que absorvem os veículos menores ou os tornam dependentes de seu conteúdo. Quanto maior as facilidades tecnológicas, maior a ação das corporações e de suas agências, mais fácil a obtenção do material disseminado por elas e maiores os riscos de os meios locais distanciarem-se de sua realidade.

No que confere ao rádio, mesmo países que até recentemente mantiveram posição muito reservada quanto à abertura comercial da mídia, como era o caso da Europa, não resistiram à privatização do setor. Multiplicou-se o número de emissoras, novas ofertas programáticas foram criadas e a publicidade assumiu papel decisivo na sustentação e desenvolvimento do meio. "A partir dos anos 80, o rádio europeu transformou-se em uma indústria." (MARTÍNEZ-COSTA, 2004, p. 332), não fugindo à tendência das fusões, da concentração da propriedade por parte dos grandes grupos e da formação de redes. Conseqüentemente, "duas décadas depois, sucumbiram muitas das iniciativas pensadas para satisfazer um público local." (FRANQUET, 2003, p. 141). Em países como França, Itália, Inglaterra e Portugal, "as rádios locais que conseguiram sucesso comercial deixaram de ser locais para se transformar em redes, e as que permaneceram locais por opção ou falta de alternativa enfrentam crescentes dificuldades." (MEDITSCH, 2001, p. 129).

Mas nada se compara ao ocorrido nos Estados Unidos, onde desde o início imperou a lei do comércio e da propriedade, intensificada, sobretudo, a partir de 1996, quando a lei das telecomunicações aboliu as regras que limitavam a 20 AMs e 20 FMs o número de emissoras por parte das companhias e indivíduos. "O resultado foi uma onda de compras e fusões nessa área." (DIZARD Jr., 2000, p. 156), acarretando "O agrupamento de estações em pequenas ou médias cadeias que, com o tempo, seriam absorvidas por conglomerados multimídia." (FRANQUET, 2003, p. 142). Para se ter idéia da voracidade dos negócios, vale citar que só no ano de 1998, cerca de 4.000 das 10.000 estações de rádio então existentes no país mudaram de mãos, em acordos que totalizaram aproximadamente US\$ 32 bilhões. Foram criadas redes regionais, nacionais e até internacionais de rádio e os mercados locais, hoje, são, em boa parte, dominados pelas grandes companhias, com a afiliação das estações locais. As que resistiram encontram dificuldades para se manter. Em 2001, um quarto do total de emissoras existentes, todas pertencentes às grandes redes, concentrava 80\% da publicidade em rádio (FRANQUET, 2003).

No Brasil, desde o início, os meios de comunicação foram controlados por oligarquias familiares, favorecidas pela forma de concessão, até o final da década passada, a cargo do poder Executivo, sob acentuada interferência política. Estudo realizado em 2001 dava conta de que grupos políticos exerciam ascensão direta sobre mais de $60 \%$ das emissoras de rádio e televisão brasileiras. A ação estende-se, inclusive, sobre as emissoras comunitárias. Mais recentemente, registra-se acentuada presença de entidades religiosas no controle da mídia. Os últimos levantamentos dão conta de que, sem contar as comunitárias, evangélicos e católicos controlam mais de 700 emissoras de rádio e TV no país (CAPARELLI; LIMA, 2004).

Além dos interesses partidários e religiosos, sobressai-se o interesse comercial, o que tem estimulado a constituição de redes, sobretudo no mercado das FMs. Estima-se que hoje 30\% do setor radiofônico do país opere por este sistema, vantajoso sob o ponto de vista econômico, pelo fato de uma emissora cabeça-de-rede produzir a programação retransmitida pelas demais praticamente sem custos (AVVALONE JORGE, 2004).

O sistema, por um lado, contribui para a modernização do rádio, na medida em que favorece 
O rádio local e o comportamento da informação na nova ordem global

a especialização em algumas áreas. A possibilidade de abranger público significativo com o recurso das redes ajuda a consolidar as emissoras especializadas em notícias ou gêneros musicais específicos, o que se torna difícil, senão praticamente impossível, para uma rádio independente do interior, com abrangência restrita e público variado, mas reduzido. O principal problema das redes é que, ao abrangerem regiões as mais diversas, não mantêm nenhuma identificação com as comunidades locais, ignoram sua cultura e não discutem seus problemas.

\section{A questão local}

Por mais que se argumente em favor da "aldeia global", da eliminação das distâncias, do espaço de fluxos, do deslocamento de imaginários e interesses, o lugar, físico e próximo, ainda exerce importância significativa para a maioria das pessoas. Como reconhece Castells (2001, p. 447):

O espaço de fluxos não permeia toda a esfera da experiência humana na sociedade em rede. Sem dúvida, a grande maioria das pessoas nas sociedades tradicionais, bem como nas desenvolvidas, vive em lugares e, portanto, percebe seu espaço com base no lugar.

A vizinhança, o bairro, a cidade ou a região urbana ou rural ainda constituem pontos de referência relativamente estáveis. As pessoas, para as mais diferentes necessidades, ainda dependem umas das outras; constroem vínculos e relações; compartilham valores, emoções, alegrias e dificuldades; reclamam, reivindicam e se organizam para resolver os problemas da vida diária, e dificilmente dispensam da memória a sensação de enraizamento num lugar (BOURDIN, 2001).

A relevância exercida pelo espaço local, portanto, requer a reforça a necessidade de meios de comunicação que contemplem essa realidade. Os veículos locais têm, neste sentido, papel insubstituível, mas que, mais que uma obrigação, deve ser visto como oportunidade. Num contexto em que a proliferação de meios e canais e a dificuldade de competir em escala mais abrangente com os conglomerados de mídia obrigam à descoberta de novos nichos de mercado, o espaço local não pode ser desprezado. Pelo contrário, esse é o lugar que se abre para o diferente, que comporta e requer o diferencial que a grande mídia dificilmente vai dar e que, por isso mesmo, apresenta-se como alternativa aos veículos que, por suas limitações, técnicas e estruturais, correm o risco de sucumbir à crescente expansão dos meios globais.

Especialmente o rádio, por suas características, tem potencial para atuação mais destacada nesse meio. É acessível, identifica-se facilmente com o público e carrega consigo a experiência adquirida de uma relação histórica com o local. Atributos não lhe faltam. Impõe-se o desafio de mostrar-se hábil, capaz e criativo para sobreviver e mesmo sobressair em meio à nova realidade.

\section{0 formato do rádio local}

A popularização dos satélites, a voracidade das redes e as seduções midiáticas que se multiplicam em todos os lugares põem contra as cordas os meios locais. Parte da crise, todavia, deve-se ao amadorismo praticado pelas emissoras, o que, no entender de Meditsch (2001), sugere um repensar da estrutura e do jeito de fazer rádio local.

A chegada e a popularização da televisão, a migração dos anunciantes e a concorrência imposta pelo próprio rádio, sobretudo a partir do advento das FMs, afetaram a arrecadação e a capacidade de investimento das emissoras. O rádio perdeu qualidade, baixou de nível e tornou-se, especialmente no caso das AMs, um veículo apelativo, tratando questões por demais pessoalizadas, com exagero na emoção e apelo ao sensacionalismo, quando não descambando para a "baixaria", em função de demasiada atenção às ocorrências do submundo das cidades, a violência, o crime, os desastres. Associado a isso, muitas emissoras encontraram na redução das equipes, no jornalismo de gilete-press ou dos conteúdos disponibilizados na internet e na terceirização de horários para instituições religiosas e outras entidades a fórmula para a sobrevivência.

Momentaneamente, saídas para a crise, estratégias dessa natureza são vistas com restrições por estudiosos da radiodifusão, para quem o rádio, a exemplo do que já estaria ocorrendo com os demais meios, frente à tendência concentradora da mídia, não conseguirá fugir ao profissionalismo, à especialização das equipes e à oferta de conteúdo 
diversificado, que atenda às preferências e necessidades dos ouvintes. Para Del Bianco (2004), ainda mais diante dos recursos (de imagens, textos, melhoria da qualidade sonora e ampliação do espectro) impostos pelo sistema digital, ou o rádio firma-se com programação de fato atrativa ou sucumbe. No entender da autora, a sublocação de horários para conteúdos deslocados do interesse da audiência, como veiculações de entidades religiosas, está com os dias contados, bem como os programas de entretenimento barato, centrados na figura do comunicador que se restringe à música e às fofocas, com pouca ou quase nenhuma informação jornalística sobre a cidade ou região. Aqueles que continuarem arraigados a um modo antigo de fazer rádio, acomodados em posições obsoletas e sem base no perfil do público, "vão perder espaço para os que souberem oferecer informação e serviço de qualidade." (DEL BIANCO, 2004, p. 321).

Na mesma linha de pensamento, Barbeiro (2004) critica o excesso de improvisação e coloquialismo e condena as orientações politiqueiras, a falta de pluralidade e o jornalismo tendencioso. Para o autor, "só a notícia de qualidade é capaz de salvar o rádio do redemoinho provocado pelas novas tecnologias eletrônicas, informáticas e cibernéticas que ativam outros meios" ( BARBEIRO, 2004, p. 144). A notícia é condição básica para a busca de resultado, mas sempre observada a credibilidade da informação e, sobretudo nos meios locais, os laços com as comunidades a que servem.

No caso do rádio do interior, onde o tamanho do público não favorece a segmentação, o formato mais aconselhável, na opinião dos especialistas, é o generalista, já adotado pela maioria das emissoras, embora nem sempre com a qualidade desejada para um veículo que se pretende que sirva à sua comunidade. Uma definição mais ou menos precisa do que se entende por rádio local é dada por Cebrián Herreros (2001b, p. 146):

A rádio local é uma emissora de programação especializada dentro de uma concepção generalista de enfoque geral sobre tudo o que concerne à localidade em que está situada. Uma rádio que atende aos interesses, responde aos gostos e necessidades de serviços de comunicação. Está centrada na vida social, econômica, política e cultural de sua área de abrangência e também em tudo o que ocorre em seu exterior e que tenha repercussões na vida da comunidade.
Como emissora de formato generalista, compete à rádio local, além da cobertura dos acontecimentos e discussão das problemáticas de sua região de abrangência, a atenção ao entretenimento, em especial à música e ao esporte, à prestação de serviço e à utilidade pública. Nas emissoras mais sintonizadas com a nova realidade do rádio, especialmente nas manhãs, predominam os programas de variedades, conduzidos por comunicadores de forte empatia com o público, com perfil "muito próximo ao de um âncora, com conhecimento dos fatos e capaz de passar credibilidade, gerando retorno de audiência." (MARCONDES apud MARANINI, 2001, p. 66). A informação, complementada por repórteres que percorrem a cidade ou intervêm no estúdio, é o principal elemento do programa que, por atender a um público heterogêneo, é aconselhável que se dedique também ao debate, à opinião responsável, às informações de serviço, ao esclarecimento sobre questões de interesse do público e, obviamente, ao entretenimento.

\section{A informação como eixo da programação}

Tanto nos programas de variedades quanto no restante da programação, a informação é elemento indispensável, pois é o que de fato confere identidade e fortalece a presença do rádio nas localidades. De acordo com Chantler e Harris (1998, p. 21):

A força do jornalismo numa emissora de rádio local é o instrumento que dá a ela a sensação de ser verdadeiramente local. Estações de rádio locais que querem atingir grande audiência e ignoram o jornalismo correm riscos. Num mercado cada vez mais disputado, o jornalismo é uma das poucas coisas que distinguem as emissoras locais de todas as outras.

Vale reforçar, porém, que a informação de real interesse do rádio local é a que está relacionada aos acontecimentos da proximidade. Quanto mais se ativer aos valores, situações e vivências próximas, maior será, na opinião de Cebrián Herreros (2001b), a sobrevivência do rádio local. "O mais importante é cobrir as notícias que os demais não dão." (CEBRIÁN HERREROS, 2001b, p. 181), mesmo que menos sensacionais. Ao rádio 
O rádio local e o comportamento da informação na nova ordem global

não convém competir com quem, por ter mais recursos, pode oferecer produtos mais espetaculares (CEBRIÁN HERREROS, 2001b, p. 157). Para Montesinos Civera (2003, p. 91), "a chave está em se conseguir com a proximidade tudo o que os demais oferecem com conteúdos."

Daí que, além de oferecer noticiosos bem definidos que permitam aos ouvintes programaremse para ouvir as notícias de seu interesse imediato, convém ao rádio estar sempre atento à realidade, interrompendo a programação a qualquer momento para noticiar um fato importante ou aportar dados novos a um acontecimento relevante já introduzido anteriormente. Sempre é importante lembrar que, por maior e mais diversificada que seja a proliferação de canais informativos, em vista das novas mídias e da especialização dos veículos tradicionais, nenhum bate o rádio na intimidade e facilidade com que trata e discute as questões que estão mais próximas da audiência, favorecido que está pela proximidade geográfica (não está se tratando de emissoras de rede, obviamente), mas também pela agilidade com que pode pôr no ar as informações. A dispensa de aparatos sofisticados na cobertura dos acontecimentos dá mobilidade ao veículo, reconhecido pela imediaticidade com que põe o ouvinte em contato com a realidade.

\section{A proposta da pesquisa}

Baseado na realidade exposta, este trabalho procurou discutir a atuação do rádio local e sua relação com a informação no Oeste de Santa Catarina (Brasil), região que mantém uma relação histórica com o rádio e onde este ainda se constitui como um vigoroso instrumento de comunicação. A investigação recaiu sobre o rádio AM, comercial, de formato generalista (a região não possui emissoras especializadas em notícias), em geral ainda preferido no Oeste catarinense, ${ }^{2}$ ao contrário do que ocorre nos grandes centros, onde a audiência das FMs bate na casa dos 70\% (LEITE, 2004). A idéia foi perceber se o rádio é de fato um meio de comunicação relevante para as comunidades em que está inserido, se atende às suas necessidades, retratando os acontecimentos e discutindo as problemáticas de seu entorno. Para a investigação, foram selecionadas cinco emissoras $\mathrm{AM},{ }^{3}$ em cinco cidades diferentes, e que se sobressaem entre as rádios mais representativas da região. A pesquisa envolveu, além de investigação bibliográfica, resgate histórico, baseado em documentos, periódicos da época e entrevistas, do rádio em Santa Catarina e, mais precisamente, da região pesquisada. Recorreu à escuta da programação, investigação de campo, com observação direta do trabalho realizado pelas emissoras, e depoimentos de empresários da radiodifusão, comunicadores e pessoas que de alguma forma estiveram envolvidas com o rádio ao longo de sua trajetória na região.

\section{0 rádio no Oeste Catarinense}

O rádio em Santa Catarina desenvolveuse à sombra das oligarquias que sempre se revezaram no comando do poder estadual. Até muito recentemente, servia aos objetivos eleitoreiros, respaldava as políticas dos governos e era instrumento de legitimação dos interesses econômicos dos grupos que exerciam o poder e daqueles que lhes davam sustentação. Especificamente na região Oeste, cumpriu papel decisivo na expansão e consolidação do complexo agroindustrial iniciado em meados do século passado, seja pelo exercício da influência política, pela difusão de tecnologias agropecuárias e mesmo pela integração que promovia entre a cidade e o interior, entre as indústrias e os criadores, numa época em que, bem dizer, era o único elo de comunicação.

A expansão e consolidação do agronegócio, até hoje o sustentáculo econômico da região, deve muito à relação instituída com os pequenos criadores, que foram naturalmente submetidos a uma posição que se pode dizer de subordinação ao modelo de capital industrial ali estabelecido. Mas foi favorecida também pela

\footnotetext{
É o que confirmam pesquisas encomendadas pelas emissoras e realizadas em três dos cinco municípios selecionados para o estudo de caso. Em dois deles (São Miguel D’Oeste e Concórdia), a audiência geral do rádio AM é, respectivamente, de 71,11 e 66\%. Em outro (Joaçaba), verificou-se um equilíbrio ( 46 a 46\%), embora a maior audiência isolada esteja concentrada em uma das emissoras AM.

3 As emissoras selecionadas foram: Rádio Peperi (São Miguel D’Oeste), Rádio Rural (Concórdia), Rádio Catarinense (Joaçaba), Rádio Videira (Videira) e Rádio Índio Condá (Chapecó).
} 
maneira como as agroindústrias souberam se articular politicamente para obter vantagens, seja por meio de políticas, fundos e incentivos direcionados ao setor, seja por melhorias na infraestrutura da região que resultassem em benefício de seus negócios. Em ambos os casos, a presença do rádio foi fundamental, o que explica a estreita relação por muitos anos mantida pelas empresas ${ }^{4}$ com o meio de comunicação. Estas tinham suas próprias emissoras, sabiamente utilizadas para a projeção política dos próprios empresários, dos grupos que lhes interessavam e como instrumento de pressão em benefício do capital, além de servir de canal de comunicação com os agricultores integrados.

A situação perdurou até fins do século passado, quando as transformações provocadas pelo processo globalizador mudaram a relação das agroindústrias com a região. Se antes havia forte relação das empresas com o lugar, em razão da maior concentração dos negócios e de acentuada dependência de decisões e políticas locais e regionais, isso deixa de existir na medida em que a abertura dos mercados pressiona para a expansão e competitividade em escala global. Além de perder o viés paternalista evidenciado no período de consolidação do complexo agroindustrial, o Estado, no novo contexto, deixa de ter papel determinante e sua própria soberania é diretamente afetada pela dinâmica do capital. Na economia global contemporânea, "é o capital empresarial global, e não os Estados, que exerce uma influência decisiva na organização, localização e distribuição do poder e dos recursos econômicos." (HELD; McGREW, 2000, p. 64).

Longe, portanto, do tempo em que o capital não podia sobreviver sem a presença do Estado e este exercia papel decisivo na alavancagem da indústria nacional, seja com recursos, subsídios ou políticas institucionais, a interferência direta ou indireta das agroindústrias na política local ou estadual perde seu sentido, tanto que a partir de meados da década de 1980, essa estratégia seria substituída pela representação dos membros das empresas "em organismos classistas dos diferentes segmentos em que atuavam." (ESPÍNDOLA, 1999, p. 57).

Ao passo que promove a desarticulação política do Estado na condução do processo de acumulação, a liberalização econômica abre as portas ao capital multinacional e inicia uma etapa de desnacionalização no complexo da agroindústria. As empresas passam por uma grande reestruturação patrimonial e produtiva, redefinem seus negócios, desfazem-se de unidades e são incorporadas por grupos que exploram outros setores, sobretudo ligados ao capital especulativo financeiro, como foi o caso da Perdigão.

A venda e a reestruturação das agroindústrias não incluem o rádio, visto que o controle político das decisões das empresas quanto a novos investimentos, expansão, empregos, etc. deixam de ter enfoque catarinense. Os proprietários, agora, são os acionistas, que não têm vínculo com o lugar e cuja localização geográfica da companhia é o que menos importa. É o que Bauman (1999) chama de "proprietários ausentes". Distanciam-se as empresas das comunidades em que estão inseridas e o rádio perde sentido para elas, haja vista o surgimento também de outros instrumentos de mediação com o produtor, como o telefone.

\section{0 rádio como negócio}

Desvinculado do complexo agroindustrial, o rádio, que antes servia de sustentação a outros negócios e interesses, passa a ser o negócio por excelência. Os novos empresários da radiodifusão visam, acima de tudo, à obtenção de resultados financeiros, lançando mão das estratégias que lhes convêm para a consecução de seus objetivos comerciais. A nova realidade impele as emissoras a se mostrarem cada vez mais agressivas no mercado publicitário, respondendo, para tanto, com programas mais atrativos e que angariem maior audiência, embora isso não necessariamente signifique equipes mais profissionais e programação de melhor qualidade.

A observação do trabalho realizado pelas emissoras e a análise da programação indicam que, politicamente falando, o rádio, ao menos no Oeste catarinense, ficou mais democrático. Obviamente que há que se levar em conta o maior rigor da legislação, ao menos nos períodos eleitorais, e o ambiente mais favorável à democracia, mas a própria necessidade de as emissoras conquistarem

\footnotetext{
4 Destacam-se, sobretudo, Sadia e Perdigão. Outra empresa importante por muitos anos foi o Frigorífico Chapecó.
} 
O rádio local e o comportamento da informação na nova ordem global

credibilidade como condição para o retorno comercial têm favorecido o acesso e o debate a todas as correntes de pensamento. Pois, tal qual observa Castells (2001, p. 301):

\begin{abstract}
se um determinado veículo de comunicação inclina-se explicitamente a uma opção política ou evita de modo sistemático certos tipos de informação, limitará seu público a um segmento relativamente pequeno, dificilmente conseguirá obter lucros no mercado e não refletirá nenhum tipo de apelo aos interesses dos diversos grupos de tendências políticas variadas. Por outro lado, quanto mais autonomia, abrangência e credibilidade o veículo de comunicação tiver, tanto mais atrairá informações, anunciantes e consumidores das mais diversas tendências.
\end{abstract}

O rádio local tornou-se, de fato, mais plural, mas nem por isso estaria mais comprometido com a abordagem de questões realmente significativas para o esclarecimento da audiência e o fortalecimento da opinião pública. Uma coisa não implica em outra. E não só o rádio, mas a mídia, em termos gerais, demonstra hoje forte sujeição aos imperativos econômicos que tocam a todo segmento que busca sobrevivência e solidificação no mercado. O rádio, enquanto negócio, é, acima de tudo, empresa a serviço do lucro.

Um dos principais problemas apontados pelos críticos da mídia, e que diz respeito também ao rádio aqui estudado, é a orientação cada vez maior da programação e dos conteúdos em função dos índices de audiência. Priorizam-se as temáticas de forte apelo popular, e o enfoque assume viés mais sensacionalista. O trágico, o chocante, o inusitado e as problemáticas de interesse humano sobrepõem-se ao conteúdo de real importância por sua repercussão social, cultural e educativa. No rádio oestino catarinense, isto é visível principalmente na prioridade dada às ocorrências da área policial, cuja veiculação em demasia contribui para uma percepção distorcida ou fragmentada da realidade.

As demais questões, todavia, não foram alijadas da programação. Pode-se dizer, inclusive, que as emissoras demonstram maior preocupação com a informação que no passado. Há um entendimento de que ao rádio local, até como forma de corresponder às expectativas da sociedade em que está inserido, compete retratar os eventos de interesse comunitário e dar visibilidade aos atores sociais. O rádio, nesse sentido, aliás, tem se mostrado bastante atuante. Não só a audiência dos setores mais influentes da sociedade é importante para o prestígio do veículo, como também o retorno publicitário oriundo da atenção dispensada ao comércio, indústria, poder público e outros segmentos de interesse.

Mas isso não necessariamente tem se traduzido em jornalismo de melhor qualidade. No caso em questão, a atuação jornalística e a eficiência na abordagem dos assuntos variam de emissora para emissora. Nenhuma delas, porém, tem investido em profissionais com formação na área, a estrutura é deficiente para o devido aprofundamento dos fatos e há visível preferência pelo factual, pelas ocorrências descartáveis, de fácil acesso e que não demandam produção mais elaborada. Não raro, preocupa-se mais com o fechamento dos noticiários que com a qualidade do conteúdo, e a recorrência ao material disponível na internet e aos jornais que chegam aos estúdios e redações é uma constante, sem que haja maior reflexão sobre a relevância das informações para a realidade da audiência. Não é costume a contextualização das notícias, nas ocasiões em que isso é possível, embora se verifique uma ou outra iniciativa de maior criatividade nesse sentido, principalmente nos programas que têm aderido a uma proposta mais moderna de jornalismo, com informativos mais dialogados e maior flexibilidade para a abordagem dos assuntos. Exemplo disso são os programas de variedades, que, aos poucos, vêm demonstrando maior familiaridade com a informação.

O tempo destinado ao jornalismo também varia de emissora para emissora. Mas, em termos gerais, pode-se dizer que todas, de alguma forma, estão atentas à realidade em que atuam e destinam maior tempo à cobertura dos fatos locais. Sem nunca perder de vista, porém, os objetivos comerciais de empresa que é. O rádio tenta, a seu modo, responder aos anseios da comunidade. Pesa o custo/benefício de suas estratégias, e mesmo as iniciativas de interesse comunitário, de maior inserção na comunidade, observam o retorno comercial imediato ou futuro da ação. 


\section{Considerações finais}

Se, no passado, havia uma submissão do rádio do Oeste catarinense ao capital e aos políticos a que as emissoras serviam, hoje a relação não é diferente. Continua-se servindo ao capital, ao negócio rádio (e também jornalístico) a serviço do lucro e, ainda que de forma indireta, aos interesses políticos e econômicos dos grupos que se servem da mídia para seus objetivos promocionais e mercadológicos. Embora sem preferências visíveis por determinadas correntes partidárias, mesmo porque já não se observam diferenças marcantes entre as propostas e práticas dos diversos partidos, as emissoras (e não é diferente com as demais mídias) deixam transparecer certo favorecimento aos grupos de poder estabelecidos. Além de praticamente dominarem os espaços destinados à informação, as questões que envolvem atores ou segmentos de influência política ou econômica, ou seja, uma elite social, são geralmente tratadas em seu aspecto positivo, relacionadas ao desenvolvimento regional, enquanto que, tal qual observa Traquina (2001, p. 112) sobre a mídia em termos gerais, "Os movimentos sociais com poucos recursos têm dificuldades em ver os seus acontecimentos transformados em notícia”, a não ser quando se sobressaem pelo "desvio", pelo pouco comum, pelos problemas ou por aquilo que possa causar transtornos à normalidade. É o caso dos agricultores, por exemplo, que comumente ganham visibilidade pelas crises, queda nos preços da produção, perda da safra por estiagem ou excesso de chuva e pela contaminação ambiental.

De qualquer modo, o rádio aí está, ocupando espaço importante e, senão de forma tão intensa quanto no passado, quando reinava absoluto, bem dizer como único instrumento de comunicação, continua sendo referencial na comunidade, na medida em que se volta à realidade próxima, retrata as problemáticas de interesse imediato e põe na ordem do dia as questões que dizem respeito ao cotidiano da audiência. O rádio local, apesar das deficiências observadas, ainda representa um diferencial em meio ao contexto multimidiático que se evidencia, em relação às novas e atrativas mídias, à multiplicação de canais, às cadeias que aceleram a concentração do setor.

Se continuará resistindo a isso, ainda é cedo para julgar, este estudo não se sente apto a responder. Mas tal qual observa Cebrián Herreros (2001a), entende que o rádio local dos novos tempos nada mais tem a ver com a antiga rádio de reprodução de discos, de baixo custo e quase nenhum profissionalismo. O novo rádio, ainda mais tendo em vista as novas tecnologias que batem à porta, a promessa cada vez maior de qualidade sonora e recursos adicionais, terá, como alerta Del Bianco (2004), que responder também com profissionais mais qualificados, equipes melhor estruturadas e informação mais adequada às necessidades da audiência, cujas preferências deverão ser diagnosticadas com métodos mais científicos.

Estes são os desafios que, no entender dos especialistas, impõem-se ao rádio local, um rádio que, por certo, vê-se ameaçado, mas ainda não sucumbiu ao curso globalizador. A concretização da aldeia global, por si só, não implica no desaparecimento da aldeia local. A aldeia local não perdeu sua relevância e continua sendo ponto de referência para a maioria das pessoas, e o rádio, enquanto instrumento de comunicação voltado a este meio, segue sendo, ao menos por ora, a voz da aldeia.

\section{Referências}

AVVALONE JORGE, Sonia Maria. Rádios FM: um contraponto entre as redes e as emissoras regionais paulistanas. In: BARBOSA FILHO, André; PIOVESAN, Ângelo; BENETON, Rosana (Org.). Rádio: sintonia do futuro. São Paulo: Paulinas, 2004.

BARBEIRO, Heródoto. Radiojornalismo cidadão. In: BARBOSA FILHO, André; PIOVESAN, Ângelo; BENETON, Rosana (Org.). Rádio: sintonia do futuro. São Paulo: Paulinas, 2004.

BAUMAN, Zygmunt. Globalização: as conseqüências humanas. Rio de Janeiro: Zahar, 1999.

BOURDIN, Alain. A questão local. Rio de Janeiro: DP\&A, 2001.

CAPARELLI, Sérgio; LIMA, Venício. Comunicação e televisão: desafios da pós-globalização. São Paulo: Hacker, 2004. 
O rádio local e o comportamento da informação na nova ordem global

CASTELLS, Manuel. A sociedade em rede. 5. ed. São Paulo: Paz e Terra, 2001.

CEBRIÁN HERREROS, Mariano. Información radiofónica: mediación técnica, tratamiento e programación. 2. ed. Madri: Síntesis, 2001a.

CEBRIÁN HERREROS, Mariano. La radio en la convergencia multimedia. Barcelona: Gedisa, 2001b.

CHANTLER, Paul; HARRIS, Sim. Radiojornalismo. São Paulo: Summus, 1998.

DEL BIANCO, Nélia. E tudo vai mudar, quando o digital cegar. In: BARBOSA FILHO, André; PIOVESAN, Ângelo; BENETON, Rosana (Org.). Rádio: sintonia do futuro. São Paulo: Paulinas, 2004.

DIZARD Jr., Wilson. A nova mídia: a comunicação de massa na era da informação. 2. ed. Rio de Janeiro: Zahar, 2000.

ESPÍNDOLA, Carlos José. As agroindústrias no Brasil: o caso Sadia. Chapecó: Grifos, 1999.

FRANQUET, Rosa. La radio ante la digitalización: renovarse en la incertidumbre. In: BUSTAMANTE, Enrique (Coord.) Hacia un nuevo sistema mundial de comunicación: las industrias culturales en la era digital. Barcelona: Gedisa, 2003.

HELD, David; McGREW, Anthony. Prós e contras da globalização. Rio de Janeiro: Zahar, 2001.
LEITE, Geraldo. Rádio FM: quem te ouviu, quem te vê. In: BARBOSA FILHO, André; PIOVESAN, Ângelo; BENETON, Rosana (Org.). Rádio: sintonia do futuro. São Paulo: Paulinas, 2004.

MARANINI, Nicolau. As transformações do AM: perspectiva da programação frente à concorrência do FM. In: MOREIRA, Sônia Virgínia; DEL BIANCO, Nélia (Org.). Desafios do rádio no século XXI. Rio de Janeiro: Intercom/UERJ, 2001.

MARTÍNEZ-COSTA, Maria Del Pilar. Tendencias de la programación. In: MARTÍNEZ-COSTA, Maria Del Pilar; MORENO, Elsa (Coord.). Programación radiofónica: arte y técnica del diálogo entre la radio y su audiencia. Barcelona: Ariel, 2004.

MEDITSCH, Eduardo. O rádio na era da informação: teoria e técnica do novo radiojornalismo. Florianópolis: UFSC/Insular, 2001.

MONTESINOS CIVERA, Jesús. Médios locales, ¿donde está la frontera de los contenidos? In: CONGRESO DE COMUNICACIÓN LOCAL (COMLOC 2002), 2. Castelló de la Plana (Espanha). In: LÓPEZ LITA, Rafael; BELTRÁN, Francisco Fernández; MORENO, Fernando Vilar (Ed.). Radio y televisión en el ámbito local. Castelló de la Plana: Universitat Jaume I, 2003.

TRAQUINA, Nelson. 0 estudo do jornalismo no século XX. São Leopoldo: Unisinos, 2001.

Recebido: $14 / 02 / 2007$ Aceito: 02/04/2007 